\title{
09. Mustafa Kutlu'nun Yoksulluk İçimizde ve Bu Böyledir hikâyelerinde modern insanın açmazı
}

\section{Ahmet KOÇAK}

APA: Koçak, A. (2021). Mustafa Kutlu'nun Yoksulluk İçimizde ve Bu Böyledir hikâyelerinde modern insanın açmazı. RumeliDE Dil ve Edebiyat Araștırmaları Dergisi, (Ö9), 107-113. DOI: 10.29000/rumelide.981510.

$\ddot{0} \mathbf{z}$

Türk edebiyatının seksenli yıllardan itibaren hem konu hem şekil hem de tür anlamında büyük bir değişim ve gelişim gösterdiği, sayısal olarak zenginleştiği bilinen bir gerçektir. İnsanlar arasında gelir düzeyinde görülen farklılıkların derinleşmesi, ülke dışına daha çok açılma ve teknolojik gelişmeler insanın teknik donanımlara ulaşmasını kolaylaştırmış, bu da beraberinde alışagelmiş bir hayat tarzının dışına çıkmaya, yeni bir ifadeyle modernleşme yolunda yeni açılımların sağlanmasına imkân tanımıştır. Moderniteye karşı duyulan özlem, teknik imkânlar sayesinde dış dünya insanının (burada kastedilen daha çok Batı insanıdır) yaşantısına ve kavuştuğu imkânlara ulaşma arzu ve çabası ülke insanında da tesirini göstermiştir. Edebî metinler bu anlamıyla özelde bireyi genelde ise toplumu yansıtan en iyi eserlerdir. Anadolu ve büyük şehir hayatını deneyimlemiş ve ikisini metinlerine çok iyi yansıtmış isimlerden birisi de Mustafa Kutlu'dur. Son yarım asrın en önemli yazarlarından biri olan Mustafa Kutlu, 1970’li yıllarda başladığı hikâye yazma serüvenini günümüze kadar zenginleştirerek devam ettirmiş nadir yazarlardandır. Kutlu'nun bu hikâye yazma serüveni neredeyse yılda bir kitap yayımlayarak devam edegelmiştir. Ayrıca Deneme ve inceleme türünde de eserler kaleme alan yazarın daha çok hikâyeye sadık kalması bile Kutlu’yu Türk edebiyatında ayrı bir yere koymaya kâfidir. Yoksulluk Iç̧imizde ve Bu Böyledir onun bu düşüncelerini en iyi yansıttığı eserler arasında sayılabilir. Bu makalede, bu iki öykü kitabından hareketle modern insanın açmazları üzerine bir inceleme yapılacaktır.

Anahtar kelimeler: Mustafa Kutlu, hikâye, Bu Böyledir, Yoksulluk İçimizde, modernizm

\section{Dilemma of modern human being in the story Yoksulluk İçimizde ve Bu Böyledir of Mustafa Kutlu}

\begin{abstract}
Mustafa Kutlu is one of the prominent figures who is well known for his precious stories in the field of Turkish storytelling and who has brought a breath of fresh air to that kind of works. M. Kutlu began to write stories in 1970s and has continued his efforts to collect them into a book. He has recently followed in the tradition to produce a piece of work at least a year. Regarding his being a storyteller, he is a productive writer. What make his works distinctive is that he has a different viewpoint of social, cultural and moral issues and that he puts them into words in a flowing style. The power of his stories can be seen in his effective use of the language that charms and impresses the reader and his authentic narration. Generally he gets his feet on the ground with respect to the issues he tells in his stories. That is the cultural historical heritage of these lands. Although in his works modern human beings use the latest facilities of science and technology and lead a much better life compared to the past, it is possible to observe they come to a deadlock without any alternatives. Among his works Yoksulluk İçimizde ve Bu
\end{abstract}

Doç. Dr., İstanbul Medeniyet Üniversitesi, Edebiyat Fakültesi, Türk Dili ve Edebiyatı Bölümü, (İstanbul,Türkiye), kocakahmet70@hotmail.com, ORCID ID: 0000-0002-0033-4188. [Araştırma makalesi, Makale kayıt tarihi: 1.07.2021-kabul tarihi: 20.08.2021; DOI: 10.29000/rumelide.981510]

Adres

RumeliDE Dil ve Edebiyat Araşturmaları Dergisi Osmanağa Mahallesi, Mürver Çiçeği Sokak, No:14/8 Kadıköy - ISTANBUL / TÜRKIYE 34714 e-posta: editor@rumelide.com tel: +90 $5057958124,+902167730616$
Address

RumeliDE Journal of Language and Literature Studies

Osmanağa Mahallesi, Mürver Çiçeği Sokak, No:14/8

Kadıköy - ISTANBUL / TURKEY 34714

e-mail: editor@rumelide.com,

phone: +90 5057958124 , +90 2167730616 
Böyledir can be considered as the ones in which he reflects these thoughts best. In this article, an analysis will be conducted on the dilemmas of modern human beings based on these two story books.

Keywords: Mustafa Kutlu, hikâye, Bu Böyledir, Yoksulluk İçimizde, modernization

\section{Giriş}

Türk edebiyatında hikâye vadisinde yazdı̆̆ı eserleriyle ayrı bir yerde konumlanan Mustafa Kutlu, özellikle bu türde yazdığı metinlerde kullandığı dil, üslup ve tema açısından da farkını ortaya koymuştur. Kutlu'nun hikâyelerinde Türkiye toplumunun yaşadığı değişim ve dönüşüm sürecini canlı ve farklı örneklerle okumak mümkündür. Bu bağlamda onun eserlerinde modernleşme ile yaşanan krizleri, köy-kent meselesini, göç olgusunu, hayatın içinde sıradan insanların yaşadığı değişim, bocalama da geniş yer alır. Bununla birlikte o, değişim ve dönüşüme uğrayan bireylerin psikolojisine ve toplumun sosyolojik yapısına da dikkatleri çeker.

1970'li yıllardan itibaren hikâye kitaplarıyla edebiyatın içinde olan Kutlu, Yoksulluk İçimizde (1981) ve daha sonra kaleme aldığı Bu Böyledir (1987) eserlerinde de modernleşmenin getirdiği olumsuzluklar, modernleşme karşısında bocalamalar, değişen iç ve dış dünya arasında sıkışmış insan psikolojisi gibi çok farklı temalara yer verir.

İnsanoğlu varoluşundan bu yana çeşitli zamanlarda açlık ve kıtlık anlamlarındaki yoksulluklarla karşılaşmış, imtihan olmuştur. Ancak yoksulluk, diğer insanlardan daha az şeye sahip olmanın dışında yaşamın temel gereksinimleri konusunda güvenden yoksun olmayı da içinde barındırır. Yoksul olmak diğer insanlardan daha az şeye sahip olmak demek değildir; aynı zamanda yaşamın temel gereksinmeleri konularında güvenden yoksun olmayı da içinde barındırır. Farklı tanımları yapılan yoksulluğun akla gelen ilk anlamı ekonomik yetersizliktir. Yoksulluk, bireyin ekonomik anlamda belli ölçülere göre alım gücünün düşük olması hatta bulunmaması, dolayısıyla hayatını idame ettirmek için birçok şeyden mahrum kalmasıdır (Şenses, 2002: 62-63). İmkânların daha kısıtlı ve az şeyle yetinmenin daha yaygın olduğu köy hayatına göre şehirlerde yoksulluk sıkça karşılaşılan bir olgudur. Yoksul olmanın veya olmamanın asıl belirleyicisi ekonomik güç, yani parasal imkândır. Bireyin yoksulluğu veya zenginliği, maddi imkânlara ne derece sahip olduğuyla ölçülür. Tüm bunların dışında bir de insanın maddi imkânlara sahip olmasına rağmen yoksul olmasını, iç huzuru yakalayamamasını ifade eden manevi açlık ya da yoksulluk vardır ki esas insanı çıkmaza sokan da budur ve Kutlu da hikâye kitabının adını Yoksulluk İçimizde koyarak buraya dikkat çeker.

Kutlu'nun Yoksulluk İçimizde eserinden sonra 1987'de ilk baskısı yapılan Bu Böyledir hikâye kitabı da hem adıyla hem de kitabın kapağında hat sanatıyla yazılan "Hiç" sözcüğü de ayrı bir mesaj verir. Bu hikâye kitabında da ele alınan konular çok karmaşık, anlaşılması ve çözülmesi zor değildir, ancak hikâyelerin okundukça farklı konulara, farklı açılımlara imkân verdiği, okuyucuyu sürekli sorularla görülenin arkasında görülmeyeni aramaya teşvik ettiği görülür. Hikâyede kendi halinde bir kasabada yaşayan insanların buraya açılan bir yol ile hayatlarının, hayata bakışlarının nasıl değiştiği, gelenekten nasıl uzaklaşıldı̆̆ı ya da geleneğe direnmeye çalışan insanların nasıl ayakta kalmakta güçlük çektikleri vurgulanır. Yeni açılan yolla beraber geleneksel değerlerin yerini, modern kent hayatının getirdiği çıkara dayalı bir anlayışın alması ve insanları değiştirmeye çalışması konu edilir. Bu yeni değerler modernizmin ve yeni kent hayatının dayattığı, insanı sürekli dış dünyaya, gösterișe, maddi olana çeken şeylerdir. Hikâye, yeni kurulan park ve onun içinde açılan lunapark metaforu çerçevesinde gelişir. Buradaki ışıklar ve sesler oraya giren herkesi içine çeken, etkisinden kurtaramayan şeylerdir. Bu durum Kutlu'nun kendisinin de dile getirdiği gibi Bu Böyledir hikâyesinde asıl mazmun lunaparktır. Çünkü lunapark dünyayı temsil eder (Dirin, 1999: 107). İçinde dönme

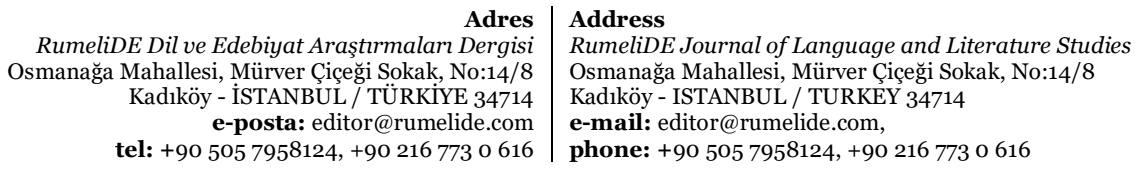


dolapların da olduğu lunapark, oyun ve eğlence mekânı, ölümün unutulduğu, dünya zevklerinin sürekli yaşandığı, gösterişin ön planda olduğu mekânlardır. Lunaparklar modern hayatın daha doğrusu modern kent hayatının getirdiği ve dayattığı bir eğlenme, vakit geçirme yeridir. Burada zamanın akıp gitmesinin de pek anlamı yoktur. Modern insan için tek bir şey önemlidir: Eğlenmek ve içinde bulunduğu zamandan, yaşadıklarından zevk almaktır. Çünkü modern hayat tarzının dayatılması ile beraber geleneksel değerler yıkılmaya başlamıș, artık hiçbir şey eskisi gibi kalmamaya başlamıştır. Lunaparktan çıkmak isteyenler de bir türlü çıkış kapısını bulamazlar. Bu yönüyle de lunapark dünyayı simgeler. Modern hayat tarzının getirdiği yeni insan tipi için asıl olan bu dünya hayatıdır ve burada yaptıklarıdır. Onun için de bu yeni insan tipi, bu dünyada ne kadar uzun yaşasa kârdır. Çünkü daha sonraki bir hayatın var olduğuna inanmaz. Hikâyede Süleyman karakterinin modern hayatla gelenek arasındaki seçim sürecinin anlatıldığı kısım, eserin vermek istediği mesajı da özetler. Süleyman, lunapark duvarı üzerinde durup Yorgancı Hafız'ın dünyası ile modern hayatın getirdiği eğlence dünyası arasında seçim yapmak zorunda kaldığında tercihini lunaparktan yana kullanır.

\section{Yoksulluk içimizde mi dışımızda mı ya da modern insanın açmazı}

Mustafa Kutlu'nun seksenli yıllarda kaleme aldığı hikâye kitabının ana teması, modern insanın her geçen gün maddeye daha çok bulaştığı, onun emrine girdiği ve bunun insanı mutlu edemeyeceğidir.

Yoksulluk İçimizde hikâyesinin konusu çok karmaşık, anlaşılması ve çözülmesi zor, okuyucuyu şaşırtan bir kurguya sahip değildir. Olay, Süheyla ve Engin arasında yaşanan ilişki sonlandıktan sonra Süheyla'nın çizgisini değiştirmesi üzerine kuruludur. Maddenin insanı mutlu edeceğini düşünen ve bu yolu tercih eden Engin ile daha sonra İslami bir hayat çizgisi seçen Süheyla aslında "madde ile mana" arasında sıkışıp kalan gençliği temsil etmektedirler. Hikâye kahramanların iç dünyalarında yaşadıkları gelgitler, bocalamalar, zaman zaman geriye dönüşler yazar tarafından iyi bir anlatım tekniği ile sunulur.

Yoksulluk İçimizde dokuz hikâye ve hikâyelerin içerisine yerleștirilen altı levhadan oluşur. Eserde yer yer Ataullah İskenderî gibi mutasavvıf şahsiyetlerin eserlerinden ve sözlerinden alıntılarla okuyucuya ayrı bir kapı aralanır. Her ne kadar hikâyeler ayrı ayrı olsa da kendi içinde bir bütün olarak tek hikâye olarak okunabilir; böylece hikâye aslında bir büyük tek hikâyeden oluşur. Tek bir hikâyeyi okuyarak anlam çıkarmak zordur. Bir bütün olarak hikâye kitabı okunduğunda anlam kazanır. Bu yönüyle Yoksulluk İçimizde'ye klasik anlamda "hikâye" demek zordur (Tonga, 2017: 45). Kutlu, gelenekten ve kıssa anlatma kültüründen ilham alarak hikâyelerinde bunu yeni bir tarz olarak uygulamıştır.

Kutlu'nun hikâye kahramanlarına seçtiği isimler de iki farklı dünyayı çağrıştırır niteliktedir. Geleneğe yaslanan Süheyla karakteri saf ve temizliği, kalbi önemseyen, ahireti de düşünen birisidir. Yeni ve modern bir isim olan Engin ise, özünde iyi olsa da hep bir hırs içerisindedir. Onun hedefi zengin olmak, daha iyi şartlarda yaşamaktır. Yoksul bir çocukluk dönemi geçiren Engin için tek hedef, dünya nimetleri daha doğrusu zenginliktir. Süheyla ise Engin'e göre her geçen gün modernleşme, diğer bir ifadeyle zenginleşmeyle beraber insanı moral değerlerinden uzaklaştıran hayata karşı bu dünya ile ahiret arasında bir denge kurmaya çalışır. Nitekim hikâyede, Süheyla'nın içe yönelik duygularının altında yatan gerçek sebeplerden birisi onun dini inançlara olan bağlığı ve oradan aldığı güçtür. Yazar bunu ayet meallerinden örneklerle destekler. "Sevdiğiniz şeylerden infak etmedikçe siz, birr'e eremezsiniz mamafih her ne infak eyleseniz Allah onu bilir." (Al-i İmran 3/92). Dolayısıyla Süheyla'nın duyguları, hayata dair görüşleri Engin için çok anlam ifade etmez. Süheyla, gerçek zenginliğin infakta olduğunu, infak ettikçe malın artacağını hatta bu infakın yani elinde olandan vermenin değerli tarafının en çok sevdiği şeylerden infak olduğunu bilir. Süheyla infak ettikçe, sevdiği şeylerden Allah için vazgeçtikçe zenginleştiğine inanır ve öyle yaşamaya

\footnotetext{
Adres $\mid$ Address

RumeliDE Dil ve Edebiyat Araştırmaları Dergisi $\quad$ RumeliDE Journal of Language and Literature Studies Osmanağa Mahallesi, Mürver Çiçeği Sokak, No:14/8 $\quad$ Osmanağa Mahallesi, Mürver Çiçeği Sokak, No:14/8 Kadıköy - ISTANBUL / TURKIYE 34714 Kadıköy - ISTANBUL / TURKEY 34714 e-posta: editor@rumelide.com e-mail: editor@rumelide.com, tel: +90 505 7958124, +90 2167730616 phone: +90 505 7958124, +90 2167730616
} 
çalışır. Engin ise hırsla sarıldığı dünya nimetleri, sahip olduğu maddi varlıklar arttıkça zenginleşeceği inancındadır. Hâlbuki böyle olunca modern hayatın dayattığı şeylere daha çok sahip oldukça insan, görünüşte zenginleşirken içerideki yoksulluğu artmaktadır. Genel olarak Türk toplumunun yaşadığı değişim ve dönüşüm estetik bir düzlemde iki farklı karakter üzerinden anlatılmaya çalışılır. Özetle her şeyin "maddi" zenginlikten ibaret olmadığı, esas zenginliğin "gönül zenginliği” olduğu vurgulanır.

Yoksulluk Iç̧imizde, bireyin kendi benliğine, içine yaptı̆̆ı yolculuğun hikâyesidir aynı zamanda. Eser, seksenli yılların Türkiye'sini anlatması bakımından mühimdir. Kısa yoldan zengin olma, zenginlikle mutluluğun yakalanacağı gibi modernitenin ve kapitalizmin getirdiği anlayışın yanlışlığı, asıl refahın ve huzurun iç benlikte olduğu, bunun yöntemleriyle örülmüş eserde, insanın asıl benliğini bulmanın önemi üzerinde durulur. Zaman zaman insan kendisinin varlık olarak kim olduğunu sorgularken içsel bir yolculuk yapar. Asıl yoksulluğun insanın içinde olduğu ve içe doğru yapılacak bir yolculukla bu yoksulluğun gönül zenginliğine çevirilebileceği anlatılmak istenir.

Aynı sosyal sınıf içerisinde yaşayan, kültürel anlamda birbirine denk olan Engin ve Süheyla'nın aşklarıyla beraber eserde, zenginlik-fakirlik, sınıf atlama, daha konforlu bir hayat yaşama arzusu, kısa yoldan zengin olma (köşe dönme), hidayete erme gibi bir dönemin (ve hala o dönemin içindeyiz) yaygın işlenen temalarına yer verilir. İnsanın esas kimliğini bulmaya, bu dünyada yaşamanın esas gayesinin diğer canlılar gibi yeme içme olmadığı, esas meselenin hakikati aramak olduğu ve hakikate ulaşıldığı zaman sükûn bulunacağı vurgulanır (Yıldırım, 2007: 41).

Hikâyede Süheyla ve Engin, çağın ortaya çıkardığı modernite çemberinin içine sıkışmış bireylerdir. Maddi refahın, zenginliğin mutluluk getireceğine inanan Engin ile Süheyla -önce o da evin içinde kaybolan tokasını saatlerce bulmaya çalışarak- dış güzelliği için gerekli olan nesnelere bağlılığıyla- mutluluğu maddi yaşamda arar. Hâlbuki hikâyede asıl refahın ve mutmain olmanın ruhta gerçekleștiği vurgulanır. Bu durum ruhunu (gönlünü) tatmin edemeyen modern bireyin önce kendisine sonra da topluma yabancılaşmasının getirdiği bir neticedir. "Giderek birbirine yabancılaşan insan yaşamlarında karşılaştıkları boşlukları obje ile doldurmaya başlar" (Özbek, 2013: 27). Bu yalnızlaşma ve yabancılaşmayı Süheyla, hikâyede anlatıcı sayesinde aşar. Onun yol göstermesi, sorduğu sorular ve farklı açılardan yaklaşması Süheyla'nın kendi içine eğilmesini sağlar. Ona derin gibi görünen ama aslında sığ olan Enginlerden kurtulmasına vesile olan anlatıcıdır.

Bundan sonra Süheyla'nın başka bir yolculuğu başlar. "Bu yolculuk" yetmişli yıllarda Türk edebiyatında ilk örnekleri görülmeye başlanan ancak seksenlerden sonra edebî metinlerde kullanımı yaygınlaşan yeni bir anlayışın, postmodern edebiyat anlayışının metinlerarası düzleminde uygulanan montaj tekniği ile yerleştirilen levhalarda dile getirilen düşüncelerle paralellik arz eder. Bu levhalardan biri Ataullah İskenderi'nin Hikem-i Ataiyye'sidir. Süheyla'ya "Eşyadan eşyaya seyahat edip durma" (Kutlu, 2015: 17) denilerek onun içinde bulunduğu yansıtılır. Süheyla "dünya suretlerinin bulaştığı ayna"nın karanlığını, etrafını saran maddi eşyalardan kurtularak parlatır. "İçindeki yoksulluğu hissediyor musun?" (Kutlu, 2012h: 17) sesi onda karşllık bulur.

Kullanılan levhalardan ikincisinde Ataullah İskenderi'den alıntı yapılır. "Ahlak Dersi" başlıklı alıntının sonunda parantez içinde "Ataullah İskenderi'nin -Öl. 1309- Hikem-i Ataiyesi'nden ilham ile" notunu düşer. Burada yazar, bütün insanlığın ortak ölçüsü olabilecek, tekrar tekrar okunabilecek ve her okunduğunda yeni mesajlar alınabilecek cümleler kurar:

"Dünya sûretlerinin bulaştığı ayna nasıl parlar? Huzura girmeden önce tevbe sularında yıkan.", "Eşyadan eşyaya seyahat edip durma. Kendine uzaktan bakmayı öğren. Bir dolap beygirine benziyorsun. Öyle ahmak,

Adres Address

RumeliDE Dil ve Edebiyat Araşttrmaları Dergisi $\quad$ RumeliDE Journal of Language and Literature Studies Osmană̆a Mahallesi, Mürver Çiçeği Sokak, No:14/8 Osmanağa Mahallesi, Mürver Çiçeği Sokak, No:14/8 Kadıköy - İSTANBUL / TÜRKIYE 34714 Kadıköy - ISTANBUL / TURKEY 34714 e-posta: editor@rumelide.com e-mail: editor@rumelide.com, tel: +90 505 7958124, +90 216773 o 616 phone: +90 505 7958124, +90 2167730616 
öyle hüzün verici.", "Hicret ve niyetin kimin için?", "Mademki içinde bulunduğun yer, konuştuğun kimse sana feyz vermiyor; terke mâni olan ne?", "Ölüme ağlama. Kalbe bak. Hata ve isyan ile pișman, ibadet ve taat ile neşveli değilsen zaten ölüsün.", Dünya nimetleri için zaafa haline düşersin. Ona doğru koşma, şükür ipi elinde ya.", "Yoksul olduğunu düşünüyorsun. Ne ki senden alınmıştır, o senin hayrınadır. İçindeki yoksulluğu hissediyor musun?" (Kutlu 2014: 17).

Metinlerarasılık Kutlu'nun hem Yoksulluk İçimizde hem de Bu Böyledir'de sıklıkla kullandığı bir metottur. Bunlar okuyucuya farklı çağrışımlar sağlarken, hikâye kişilerine de yol gösterici niteliğindedir. Modern insanın karşılaştığı soruların cevabı asırlar öncesinde pek çok şahsiyet tarafından cevabı verilmiştir. Dolayısıyla her şeyi madde ile çözeceğini ve huzura erişeceğini düşünen modern insana çıkış yolu gösterecek reçeteler gelenekte vardır.

\section{Modern hayat lunaparkta Süleymanlara yolunu kaybettiriyor}

Bu Böyledir hikâyesi genel hatlarıyla Anadolu'nun sakin bir kasabasında yüzyıllardır devam eden geleneksel yaşam tarzının ovanın ortasından açılan yolla nasıl değiștiği anlatılır. Yazar bunu bazen hikâye kişileri bazen de Yorgancı Hafız’n dükkânı gibi belli semboller üzerinden verir. Hikâyenin ana kahramanı Süleyman Koç, lisede hep felsefeden sınıfta kalmıș, hayatta pek başarılı olamamış, hayallerini gerçekleştirememiş biridir. Süleyman'ın gençlik yılları annesiyle birlikte yoksulluk içinde geçer. Bu sıkıntılı dönemde Süleyman, hem Hafız Yaşar'dan hafızlık dersleri alır hem lisede ikmale kaldığı felsefe dersini geçmek için uğraşır hem de yazları tuğla ocaklarında çalışarak para kazanır.

Yolla beraber kasabaya lunapark açılmış ve burada yaşayan insanların hayatı da yavaş yavaş değişmeye başlamıştır. Süleyman Koç, karısı ve çocuğuyla gittiği bu lunaparktan çıkmak bilmez, çıkacağı zaman da çıkış kapısını bulamaz. Bu aslında modern insanın açmazı ya da dünyanın göz alıcı eşyaları arasında insanın kaybolup gitmesini temsil eder. (Andı, 2008: 72).

Süleyman, varlıklı, zengin bir ailenin bir ailenin çocuğu değildir. Hikâyede anlatıldığı kadarıyla kasabada yaşayan ortalama bir Anadolu delikanlısıdır. Anası "Dulayșe Bacı"nın aldığı emekli maașı kendisi ile dört yetimine yetmediği için yoksulluğun ne olduğunu bilen biridir. Ailesine destek olmak için, özellikle yaz tatillerinde tuğla ocaklarında çalışır. Kışın okulda yaz tatillerinde tuğla ocağında çalışan Süleyman'ın elleri kırmızı tuğla tozlarına boyanır, tuğla gibi elleri pişer. "Kara- kavruk bir yüz", "incecik kollar ve bilekler"e sahip hikâye kahramanı tuğla ocağındaki banyolarda değil, "ırmakta yıkanıp yorgunluğunu giderir." Süleyman'ın hiç yeni gömleği, yeni ayakkabısı olmamıştır, düğünlerde giyebileceği yeni pantolonu da yoktur. Hatta kuru temizlemeciye pantolonunu temizletmek için verdiği zaman, kalfa pantolonu alırken, bunun nesi temizlenecek anlamında, bir pantolona bir de onun yüzüne bakar. Evlendiği zamanda ailesi üzerinde baskın bir karakter olamaz, çünkü Süleyman'ın hayatı kayıktır. Doğru dürüst okulunu bile bitirememiş, diplomasını alamamış birisidir o. Belli bir işi, sabit bir geliri olmayan hikâye başkişisi, memur olarak bir bankaya girse de aldığı ücret yeterli değildir. Eşinin istediği "bir yatak odası takımını" bile alamamıştır. Parası olduğu zaman yapacağı ilk işlerden birisi kiracılıktan kurtulup ev almaktır. Lunapark içinde çarpışan taksilerde herkes önüne gelene çarpmaya, vurmaya alışkınken, Süleyman orada da kimseye çarpmamaya dikkat eder. Bu yönleriyle o, hedefi pek belli olmayan, içinde bulunduğu şartları biraz daha iyileştirmek isteyen ama bunu da nasıl yapacağını bilemeyen birisi olarak ortaya çıkar. Bu noktada Süleyman'a kılavuz olan, ona yeni kapılar açacak olan Yorgancı Hafız Yaşar'dır. Yorgan ustası Yaşar, dünya ile ahiret arasında iyi bir denge kurmuş, vakit namazlarını camide kılmaya özen gösteren biridir. Onun soruları, yönlendirmeleri Süleyman'un ufkunu açar. Kasabaya yolun açılması, lunaparkın kurulmasıyla beraber insan-doğa ilişkileri, hayata bakış açısı da değişmiştir. Bu modern hayatın getirdiği ya da dayattığı yeni bir hayat anlayışıdır. Süleyman'a öğretilen ya da Hafız Yaşar'ın kendisine durmadan söylenenleri

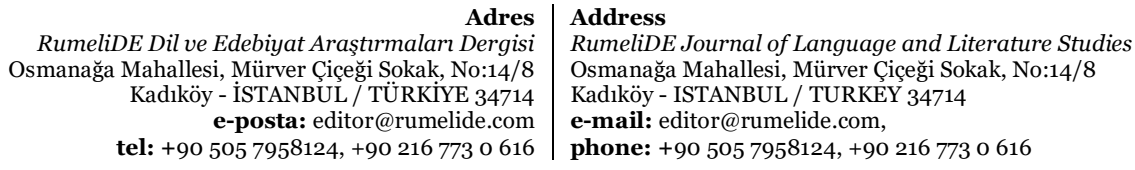


yapmak zorunda kaldığında, "elmaları, armutları, zerdalileri, asmaları, hatta gülleri hepsini tez elden kesmek"tir. Çünkü modern insanın beklemeye, zamana tahammülü yoktur ve amacı en hızlı șekilde hedefe ulaşmak olmalıdır. Bunun için bu sulak arazilere "tez elden kavak ağacı" dikilmelidir. Çünkü kavak ağacı fazla emek gerektirmeyen, ekeni "senesine varmaz, servete boğacak" bir üründür. Bunun dişında başka alternatifler de vardır. Hedeflerinden biri, yeni açılan yolun kenarında bir benzin istasyonu işletmektir. Buna gücü yetmezse, varlıklı birisinin açtığı benzin istasyonuna ortak olmaktır. Tüm bunlar kâr-zarar hesabında hep kazanmak üzerine kurulu ilişkiler ya da yatırımlardır. Çünkü yeni anlayışla beraber Süleyman'ın hayata bakış açısı da değişmiş, daha çok kazanma, kârlı işlere yatırım yapma anlayışı hâkim olmaya başlamıștır. Yeni anlayışla beraber insan tabiat ilişkisi değiştiği gibi insanlar arası ilişkiler de menfaat üzerine kurulmuştur. Artık herkes, evlerini, bağ ve bahçelerini, ağaçlarını hep bir hesap kitap üzerine bina etmektedirler. Hatta modern hayatla beraber zaman kavramı bile değişmiş, "insanlar artık geç yatıp, geç kalkmaya" başlamıştır. Hâlbuki Yorgancı Yaşar’a göre "Gece gecedir, gündüz de gündüz." Gündüz çalışma, rızkının peşinden koşma zamanı, gece de uyku ve ibadet vaktidir (Uçan, 2000: 50-51).

Hikâyede modern hayatla beraber şehirlerdeki mimari yapıların da değişmeye başladığı, çok katlı, komşuluk ilişkilerinin neredeyse ortadan kalktığı, birbirinden habersiz şekilde apartman hayatının her geçen gün yaygınlaştığı eleştirisi de yapılır. "Çok katlı binalar, mağazalar, tıkış tıkış arabalar" iç karartıcı bir ortam oluşturmakta ve her geçen gün hayatı katlanılmaz hâle getirmektedir. Bu yeni hayatla beraber esnafın alışveriş alışkanlığı da değişmiştir. Yeni türedi esnaflar, insanların parasını alıp ortadan kaybolmaktadırlar. Modern hayatın getirdiği alış veriş çılgınlığı ya da yeni hayatın dayattı̆̆ı eşyalara sahip olmak için faiz sistemi yaygınlaşmıştır. Dolayısıyla insanın çevreden başlayarak aile içindeki ilişkilerine kadar bir bozulma söz konudur. Hep bir hedefi vurma peşinde olan Süleyman, bir türlü hedefi tutturamaz. Aslında yeni hayatla beraber bu labirent içinde sürekli dolanıp duran ve gerçek hedefi kaybeden insanın macerasıdır Enginlerin, Süleymanların, Şinasilerin hikayesi.

\section{Sonuç}

Mustafa Kutlu yetmişli yıllarından sonlarından itibaren başladığı hikâye kitaplarıyla yazdığı Türk edebiyatında ayrı bir yere oturmuştur. Hikâyelerinde toplumun geçirdiği toplumsal değişimleri, değişim yaşanırken bireylerin yaşadığı sorunları, modernitenin dayattığı dünyevileşmeyi, kent-köy arasında yaşanan bocalamayı, arada kalmışlığı, göç olgusunu, toplumun ve insanın dış zenginliği artarken iç zenginliğinin boşaldığı gibi pek çok meseleye yer verir. Onun seksenli yılların hemen başında kaleme aldığı Yoksulluk İçimizde ve daha sonraki eseri Bu Böyledir'de modern insanın çıkmazlarına yer verir. Kısa yoldan köşe dönmenin, daha çok paraya ve maddiyata sahip olmanın sürekli şuur altına işlendiği bir ortamda, asıl zenginliğin gönülde ve içerde olduğuna dikkat çekilir. Bunu zaman zaman hikâyelerde hayata bakış açıları farklı karakterler üzerinden yapar. Yoksulluk İçimizde hikâyesinde Engin ve Süheyla böyle karakterlerdir. Okuyucu bu iki insanın hayata bakış açısı, iç konuşmaları, anlatıcının araya girerek yol göstermeleri ile madde ile mana arasında bir denge kurmaya çalışır.

Bu Böyledir'de de Mustafa Kutlu, hayatı hep ıskalamış, yokluklar içinde hayata tutunmaya çalışan Süleyman'ın ve Şinasi'nin hikâyesi üzerinden modern hayatın açtığı yolda yolunu kaybeden bir girdiği lunaparktan çıkamayan insanın macerasını anlatır. Aslında dünya denen dönme dolapta insan belli bir süre eğlenmekte ve sonra geldiği yere geri dönmektedir. Ancak lunaparkın içinde yer alan ve insanı cezbeden eşyalar gibi insan da bu dünyanın gösterişine aldanmakta ve yolunu kaybetmektedir. Hâlbuki esas olan iki dünya arasında denge kurabilmektir. Her iki hikâye kitabının ortak temasının modern insanın açmazını dile getirmek ve onun bu açmazına kimi zaman hikâye kişileri, kimi zaman da anlatıcının araya girmesiyle yol göstermek olduğunu söylemek mümkündür.

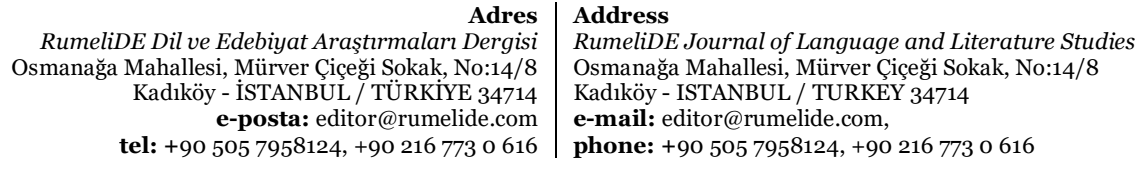




\section{Kaynakça}

Aktulum, K. (2000). Metinlerarası İlişskiler, Ankara: Öteki.

Andı, M. F. (2008). “Metinlerarası İlişkiler Açısından Mustafa Kutlu'nun Bu Böyledir İsimli Eseri”, (hz. M. Fatih Andı, Ömür Ceylan, Öykünün Bugünü Bugünün Hikâyesi: 80 Sonrası Türk Hikâyesi Sempozyumu, İstanbul: Ümraniye Belediyesi Yayınları, s. 71-82.

Atiker, E. (1998). Modernizm ve Kitle Toplumu, Konya: Vadi.

Dirin, İ. (1999). “Söyleşi: Mustafa Kutlu İle Öykücülüğü Üzerine”, Hece Dergisi, S. 33-34, s. 106-123.

Ecevit, Y. (2009). Türk Romanında Postmodernist Açllımlar, İstanbul: İletişim.

Keș, İ. (2019). “Toplumsal Değișme Bağlamında Mustafa Kutlu Beșlemesi”, Necmettin Erbakan Üniversitesi, Sosyal Bilimler Enstitüsü, (Yayımlanmamıș yüksek lisans tezi), Konya 2019.

Kutlu, M. (2006). Bu Böyledir, İstanbul: Dergâh.

Kutlu, M. (2015). Yoksulluk İçimizde, İstanbul: Dergâh.

Şenses, F. (2002). Küreselleşmenin Öteki Yüzü: Yoksulluk, İstanbul: İletişim.

Tonga, N. (2017). "Her Daim Bir Mustafa Kutlu Klasiği: Yoksulluk İçimizde”, Hangâh, S. 3, Eylül-Ekim-Kasım 2017, s. 45-46.

Tosun, N. (2004). Türk Öykücülüğünde Mustafa Kutlu, İstanbul: Dergâh.

Uçan, M. H. (2000). “Batı'da ve Bizde Roman, Öykü, Anlatı Teknikleri ve Bir Mustafa Kutlu Öyküsü: Bu Böyledir", Nisan 2000, s. 43-53.

Ylldırım, E. (2007). Mustafa Kutlu Hikâyeciliği Varoluş/Yabancılaşma/ Hakikat, Ankara: Ebabil.

RumeliDE Dil ve Edebiyat Araştırmaları Dergisi Osmanağa Mahallesi, Mürver Çiçeği Sokak, No:14/8 Kadıköy - İSTANBUL / TÜRKIYE 34714 e-posta: editor@rumelide.com tel: +90 $5057958124,+902167730616$
Address

RumeliDE Journal of Language and Literature Studies Osmanağa Mahallesi, Mürver Çiçeği Sokak, No:14/8

Kadıköy - ISTANBUL / TURKEY 34714

e-mail: editor@rumelide.com

phone: +90 $5057958124,+902167730616$ 